$\xi=-1$

\title{
Comparison of an effective working hour and harvesting cost between manual harvesting (chisel and sickle) and mechanised harvesting (CKAT and motorised cutter) in oil palm plantation.
}

\author{
Muhammad Aliuddin Bakar', Nur Firdaus Abdul Rashid², Syahrizan Syahlan \\ ${ }^{1,2,3}$ Faculty of Plantation and Agrotechnology, Universiti Teknologi MARA (Melaka) \\ *Corresponding author E-mail: aliuddin@melaka.uitm.edu.my
}

\begin{abstract}
From this paper, it is an effort to investigate the most efficient harvesting tools that must be applied by all oil palm producers. It is similar to identify which harvesting tools are the most efficient that reflected the labour productivity and cost management for harvesting operation. The motorised cutter, mechanised CKAT, manual chisel and manual sickle were tested based on capacity and cost involved. EFC for motorised is superior to manual with 0.29 ha per hour for motorised and 0.22 ha per hour for manual. The trials carried out on manual harvesting technique by using chisel shows that effective working hour per hectare is 1.64 ha per hour and effective working hour per hectare for mechanised harvesting technique is 1.84 ha per hour. Also, the cost involved in both harvesting tools, the motorised cutter price is RM 4500 plus its operational costs, the harvesting cost comes to RM 8.78 per tonne, and for the manual sickle cost is RM 143 plus its operating cost, it comes to RM 10.14 per tonne. Furthermore, the cost for manual chisel is RM 80 and the cost per tonne for manual harvesting technique is RM 22.35 and cost for CKAT is RM1500 plus and cost per tonne for CKAT is RM 24.05. Therefore, by using the motorised cutter, the estate would reduce $50 \%$ of its labour requirement in the harvesting operation.
\end{abstract}

Keywords: Manual harvesting; mechanised harvesting operating cost

\section{Introduction}

Agricultural sector acts as the primary contributor to the Malaysia economy, in particular for the first 30 years after our nation achieved independence (1). The agriculture sector, especially oil palm was playing a prominent role in consolidating national economy since the production is expected to contribute RM 100 billion by 2020 (2). Oil palm (Elaeis guineensis) becomes a priority to be planted because of the suitability of the plant that can grow with the Malaysia climate and the cash generated from the oil palm production. Development of oil palm mainly to provide employment for local people and to meet the demand of human for oil palm by-product such oil and fat (Wastie and Earp, 1972) food and others.

\section{Problem Statement}

The manual technique of harvesting fresh fruit bunches for small palm includes the utilisation of a chisel and sickle, which requires more physical work and time. It needs the ability and additionally strength to guarantee a viable cutting operation. Trouble in getting talented harvester and routes on the most proficient method to enhance harvesting efficiency has turned into a need. According to (3), the present manual harvesting technique can just harvest 5060 fresh fruit bunches per hour. Oil palm plantation is presently searching for more efficient harvesting tools which can increase the output with a specific end goal to build individual daily harvesting output and lastly diminishing the quantity of worker. Me- chanical harvesting technique of fresh fruit bunches becomes the main point that should be settled. To overcome this problem, the Malaysian Palm Oil Board (MPOB) has introduced an innovation harvesting tool known as Motorized Cutter. The motorised cutter divided into two forms such as CKAT for short palm harvesting and CANTAS for intermediate palm harvesting (3). Unfortunately, this motorised cutter still lacks and little of utilisation in oil palm plantation. It is possible that the information about motorised cutter had not reached to them properly. Moreover, lack of broadcasting study in a comparison between manual harvesting technique and mechanical harvesting technique for small palms to determine which one of harvesting technique can give better returns.

The objectives of the studies are:

To determine the effective field capacity of manual harvesting and mechanised harvesting applications in oil palm harvesting practices.

To determine the cost of manual harvesting and mechanised harvesting applications in oil palm harvesting practices

\section{Literature Review}

Oil palm was planted commercially by producer in Malaysia for commercial purpose has approximately in 5.0 million hectares. According to (4), oil palm production was shown to significantly increase from 94,000 tonnes in 1960 to 15 million tonnes that recorded in 2005. The production was increased up to 160 times for 45 years. The increasing world demand, especially for oil and fat and stable price makes the palm oil attractive to be selected than other commodity crops such as rubber, cocoa and pineapple. 
For that reason, the expansion of the oil palm plantation area leads to the needs of labours to accomplish tasks in the field. Since the oil palm producers are facing a shortage of labour to harvesting process, an alternative is required to reduce the manpower energy to the harvesting process. Harvesting is the most critical operation because the productivity depends on the efficiency of harvesting. Nowadays, on plantation sector mostly still using manual harvesting, which is slow and uses a lot of labour energy. So, there has some estate try to applying mechanise harvester for oil palm. The main advantages of mechanised harvesting are speed and the reduced costs per tonne harvested.

Mechanisation practices were compromised from fully mechanised and semi-mechanized that implementing in the plantation was conducted from planting, manuring, weeding, pesticides and chemical application, harvesting until transported the yield to processing mills. By that, precision agriculture in plantation such as the motorised cutter is recommended to solve the problem that faced oil palm producer in the harvesting operation. According to (5), the use of mechanisation can increase labour productivity in the plantation sector. This innovation can be lead plantation to reduce the dependency on labour and acquire labour cost saving for long term period. Other than that, the uniformity and higher worker productivity by using the mechanisation can give advantages since the plantation wants to achieve the sustainability of profit and reduce the cost involved.

Given the present pattern, an unbeneficial stage might be obtained by the oil palm plantation to suit additional increments in worker cost. Consequently, there is a requirement to boost the used of mechanisation in oil palm plantation to diminish work reliance and expense of production. Mechanisation has likewise been proposed as a way to enhance efficiency and reduce the portion of the difficult job now being performed manually.

For example, harvesting process in oil palm plantation nowadays has been through the process utilisation of mechanisation. Harvesting the fresh fruit bunches can divide into two sections which are manual harvesting technique and mechanical harvesting technique. The manual harvesting technique usually will use the chisel or sickle to harvest the fresh fruit bunches and mechanical harvesting technique will use mechanised tools such as CKAT or CANTAS designed by the Malaysian Palm Oil Board (MPOB) to increase the productivity of harvester and reduced worker requirement in oil palm plantation.

\section{Experimental}

\subsection{Location of study}

The comparison of manual harvesting technique by using a chisel and mechanical harvesting technique by using CKAT was conducted in the various oil palm site owned by smallholder located in Bukit Lintang, Melaka. The available criteria on the oil palm site such as young palm trees, the height of palm trees just reached approximately 4 to 5 feet and early harvesting years caused that this oil palm site is suitable to carry out for this case study. Moreover, the owner of motorised cutter already used the CKAT for two years facilitates the further process of data collection for this case study.

This study compares two types of harvesting tools for small palms which are chisel and CKAT.

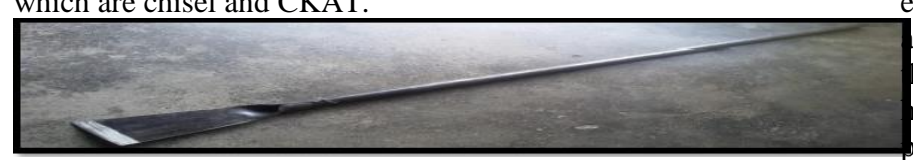

Fig. 1: Manual harvesting tool Chisel

Table 1: Comparison between manual harvesting technique

\begin{tabular}{|c|c|c|}
\hline Item & Chisel & Sickle \\
\hline Specification of a Length & $1.5 \mathrm{~m}$ & $3.5-5.5 \mathrm{~m}$ \\
\hline Weight & $4.0 \mathrm{~kg}$ & $7-8.5 \mathrm{~kg}$ \\
\hline Price & RM 80.00 & RM 143.00 \\
\hline
\end{tabular}

The manual harvesting technique of short palms is typically complete by utilising a chisel attached to a hollow metal pole, usually galvanised iron. The length of chisel blade is 7 inch and width of chisel blade is 4 inches. This type of harvesting tool is suitable to harvest fresh fruit bunches from a palm that have height below 3 $\mathrm{m}$. Hitting chisel at a fast to frond or fresh fruit bunches stalk is a consequence during the harvesting process by using manual harvesting tools. To complete the harvesting process, the harvester needs adequate distance around him so he can create sufficient force to hit the chisel and cut through the material. The level of success depends significantly on the efficiency of the chisel utilised with harvester experience and skills.

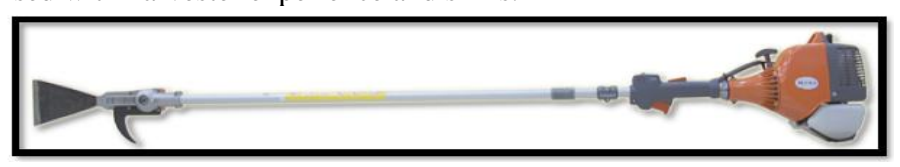

Fig. 2: Mechanised harvesting tool (CKAT)

Table 2: Comparison between mechanised harvesting technique

\begin{tabular}{|c|c|c|}
\hline Item & CKAT & Motorized Cutter \\
\hline Specification of a Length & $2.1 \mathrm{~m}$ & $1.2-2.4 \mathrm{~m}$ \\
\hline Weight & $6.0 \mathrm{~kg}$ & $7.5-8.5 \mathrm{~kg}$ \\
\hline Price & RM $1,500.00$ & $\mathrm{RM} 4,500.00$ \\
\hline
\end{tabular}

CKAT utilises the same engine and head as CANTAS but it is attached with a sickle for harvesting fresh fruit bunches. CKAT includes a pole, cutting head and 2-stroke petrol engine of $25.4 \mathrm{cc}$ $(1.3 \mathrm{hp})$. It was formed for harvesting palm from $1.2 \mathrm{~m}$ to $2.4 \mathrm{~m}$. This mechanised cutter can give a quick, simple and safe pruning and harvesting for those difficult to achieve operation. The light weight model and easy controls can guarantee the maximum comfort to the harvester when utilising CKAT. Besides, the extendable shafts and optional tension give added reach to cutting adaptability of frond base and bunch stalk. Motorised cutter is being adapted with fast acceleration gear along balanced transmission for optimum cutter success.

\section{Data Collection}

Data collection can be defined as the process of accumulating data for a specific objective from different types of sources which include observation, interview, questionnaire, existing records and electronic devices. This process is for initial to statistical analysis of the data. The study used direct personal investigation to accumulate data. The meaning of direct personal investigation is the collection investigator gather data personally which sources relevance. Therefore, the investigator has to be concerned, polite, alert and must be there at study area when inquiry is being conducted. The different parameters were assessed for these two types of harvesting technique and a comparison was measured to decide which harvesting technique that can give more benefit to harvester to fulfil harvesting task.

The collection of data for comparison between manual harvesting technique by using a chisel and mechanical harvesting technique by using CKAT was gathered through a record of the time taken of harvesting fresh fruit bunches and the number of fresh fruit bunches productivity. The time consumption to harvest palm tree and the number of fresh fruit bunches productivity was all recorded. The recorded time of these two harvesting techniques by using chisel and CKAT were obtained to compare the time taken for he cutting operation. Time consumption was the time taken by the arvester to cut fronds and bunches from starting point to end oint. The process of recording the time consumption data has done for one month for each of harvesting techniques.

Besides, the collection of data also gathered through interviews the owner of the motorised cutter about cost needed to complete each harvesting task. There are different types of cost which have to take consideration and record to fulfil the harvesting cost calculation. The cost of repair, fuel, lubricant and labour is an example of a cost that needs to register properly to determine which har- 
vesting technique that can give more benefit to harvester to fulfil harvesting task.

\subsection{Data analysis}

The collection of data will be calculated by using the average data for simpler the way to get the results. All data recorded will transfer to Microsoft Excel Software for easy to analyse. Microsoft Excel used as the first place to record the data needed in achieving the objective of the case study. Bar chart also produced from the Microsoft Excel software.

\section{Results and findings}

Effective field capacity for both harvesting operations is shown in Table 3. The same formula was used to calculate the coverage area for both operations in the field. Times taken will be converted from second (S.I unit) into hour basis. Time taken for motorised cutter practices to complete the overall task is better than the manual practices. For manual harvesting, the workers work 5 hours per day because of exhausted of energy and motorised cutter can operate up to 8 hours because the motorised cutter needs less of energy during operation compare to manual harvesting. Effective field capacity for manual harvesting can cover an area of 0.22 ha per hour and 0.29 ha per hour for motorised cutter operation. The EFC for a motorised cutter is greater than the manual harvesting operation.

Table 3: Effective field capacity (EFC)

\begin{tabular}{|c|c|c|c|c|c|}
\hline $\begin{array}{l}\mathbf{N} \\
\mathbf{0}\end{array}$ & & Chisel & Sickle & $\begin{array}{l}\text { Motorized } \\
\text { Cutter }\end{array}$ & CKAT \\
\hline 1 & $\begin{array}{l}\text { Cover- } \\
\text { age area }\end{array}$ & $\begin{array}{l}2 \quad \mathrm{mi}- \\
\text { nute/palm } \\
30 \mathrm{palm} / \mathrm{hr} \\
\mathrm{x} 5 \mathrm{hr} \\
\text { working } \\
=150 \\
\text { palms / } \\
136 \\
=1.1 \mathrm{ha}\end{array}$ & $\begin{array}{l}1.38 \quad \mathrm{mi}- \\
\text { nute/palm } \\
83 \mathrm{palm} / \mathrm{hr} \\
\mathrm{x} 5 \mathrm{hr} \\
\text { working } \\
=\quad 415 \\
\text { palms } \\
136 \\
=3.05 \text { ha }\end{array}$ & $\begin{array}{l}1.5 \mathrm{mi}- \\
\text { nute/palm } \\
40 \mathrm{palm} / \mathrm{hr} \\
\mathrm{x} \quad 8 \mathrm{hr} \\
\text { working } \\
=320 \mathrm{palm} \\
/ 136 \\
=2.35 \mathrm{ha}\end{array}$ & $\begin{array}{l}1.22 \mathrm{mi}- \\
\text { nute/palm } \\
73 \mathrm{palm} / \mathrm{hr} \\
\mathrm{x} \quad 8 \mathrm{hr} \\
\text { working } \\
=588 \mathrm{palm} \\
/ 136 \\
=4.32 \mathrm{ha}\end{array}$ \\
\hline 2 & $\begin{array}{l}\text { Time } \\
\text { taken }\end{array}$ & $5 \mathrm{hr}$ & $5 \mathrm{hr}$ & $8 \mathrm{hr}$ & $8 \mathrm{hr}$ \\
\hline 3 & $\begin{array}{l}\text { Effec- } \\
\text { tive field } \\
\text { capacity } \\
\text { (EFC) }\end{array}$ & $\begin{array}{l}1.1 \text { ha } / 5 \\
\text { hr } \\
=0.22 \text { ha } \\
\text { per hour }\end{array}$ & $\begin{array}{l}3.05 \text { ha } / 5 \\
\text { hr } \\
=0.61 \text { ha } \\
\text { per hour }\end{array}$ & $\begin{array}{l}2.35 \text { ha } / 8 \\
\mathrm{hr} \\
=0.29 \text { ha } \\
\text { per hour }\end{array}$ & $\begin{array}{l}4.32 \text { ha } / 8 \\
\text { hr } \\
=0.54 \text { ha } \\
\text { per hour }\end{array}$ \\
\hline
\end{tabular}

Table 4: Summary of cost involved

\begin{tabular}{|c|c|c|}
\hline \multirow{2}{*}{ No } & \multirow{2}{*}{ Cost component, $R M$ day $^{-1}$} & Chisel \\
\hline & & Cost (RM) \\
\hline 1 & Fixed cost & 0.48 \\
\hline 2 & Repair and maintenance & 0.14 \\
\hline 3 & Fuel consumption & - \\
\hline 4 & Lubricant cost & - \\
\hline \multirow[t]{3}{*}{5} & Operators & 42.07 \\
\hline & Total cost, $\mathrm{RM}$ day $^{-1}$ & 42.69 \\
\hline & Total cost per tonne, $R M$ ton $^{-1}$ & 10.14 \\
\hline
\end{tabular}

As shown in Table 3, the field capacity by manual harvesting technique higher than mechanised harvesting technique. Field capacity for manual harvesting technique is 0.61 ha per hour and field capacity for mechanised harvesting technique is 0.54 ha per hour.

\subsection{Summary Cost Involved}

The cost of both harvesting tools operations that shown in Figure 3 is different compared to each other. The motorised cutter is low compared to manual sickle with a pole. The rate to cover one tonne by using manual approach is RM10.14 and by using motorised is RM8.78 per tonne.

The time was taken and proportional for these two different harvesting tool is shown in this table 4 . The proportional transferring the FFB and loose fruit to platform task for both tools has the highest time consuming compared to other tasks, with manual tools $40.3 \%$ and $50.2 \%$ for motorised. Travelling to others palm has the lowest proportional which recorded $3.6 \%$ and $4.5 \%$ for manual and motorised.

Time consumption of each task for both practices is shown in figure 4 . The difference between this two practice can be seen on the pruning and harvesting the oil palm (task 1 and task 2). There is no different time consuming for others task.

\subsection{Paired T-Test and CI: manual, motorised}

Paired T for manual - motorised

$\mathrm{N}$ Mean StDev SE Mean

$\begin{array}{lllll}\text { manual } & 6 & 46.3 & 35.4 & 14.5\end{array}$

$\begin{array}{lllll}\text { motorized } & 6 & 37.2 & 38.8 & 15.9\end{array}$

$\begin{array}{llll}\text { Difference } 6 & 9.17 & 14.29 & 5.83\end{array}$

95\% CI for mean difference: $(-5.83,24.16)$

T-Test of mean difference $=0($ vs not $=0)$ : T-Value $=1.57 \mathrm{P}$ Value $=0.177$

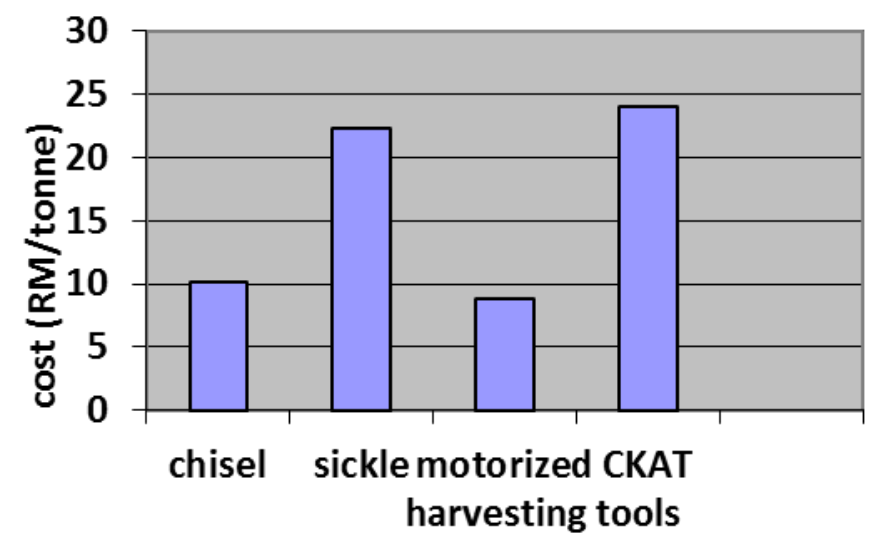

Fig. 3: Comparison on cost of both harvesting applications

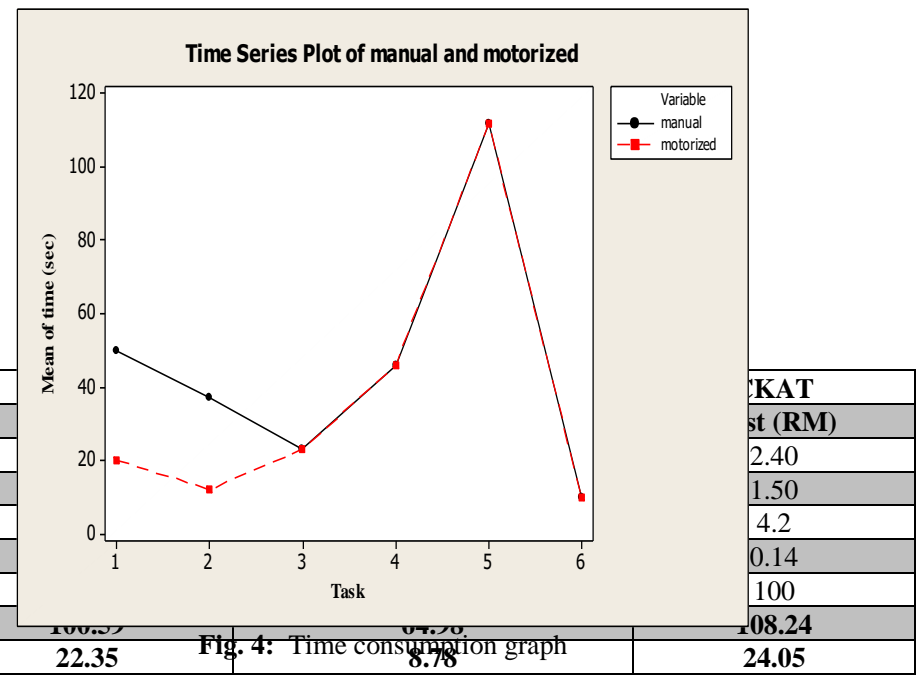

The study highlighted and calculated the results based on the objectives of the case study and calculated the data that has been collected. Data collection for comparison between manual harvesting technique and mechanised harvesting technique was taken for a month. Example of data collected is time-consuming to harvest the fresh fruit bunches for one hectare per day and total harvesting cost needed to harvest the fresh fruit bunches for both harvesting techniques.

All the collected data for manual and mechanised harvesting technique will be calculated by using average data and transfer to Microsoft Excel Software in order to determine the proper result. Effective working hour per hectare, time taken to cut a bunch, average fresh fruit bunches per hour and cost per tonne is the example of a result that needs to be calculated and compare for both manual and mechanised harvesting techniques. 


\subsection{Effective Field Capacity}

Until nowadays there is still no any tools or a specific equipment that efficient to use for harvesting FFB. From this study there is no practice can meet all the needs of oil palm plantation because of the different management, field condition and terrain that is available in the field area. Since this study comparing just two methods or tools for harvesting operation, careful consideration is required to ensure the plantation can achieve an optimum performance of harvesting tools. The estate normally chooses whether to implement manual sickle or motorised cutter in their estate. The estate will select the best practices that can give a better productivity with the lowest cost to gain a maximum profit. Based on the result in chapter four, it can be included that the motorised cutter is more productive than manual sickle. Effective field capacity (EFC) for manual is much lower than motorised cutter $(0.22<0.29$ hectare per hour).

According to the results, field capacity by utilising manual harvesting technique is 0.61 ha hr-1 and field capacity by utilising mechanised harvesting technique is $0.54 \mathrm{ha} \mathrm{hr}-1$. This shows that field capacity by utilising manual harvesting technique is increased by $11 \%$ compared to utilising mechanised harvesting technique.

Comparison of cost per tonne between manual harvesting technique and mechanised harvesting technique also was calculated Cost per tonne by utilisation chisel is RM 22.35 and cost per tonne utilisation CKAT is RM 24.05. The result shows that cost per tonne for manual harvesting technique is lower compared to mechanised harvesting technique.

The result shows that manual harvesting technique by utilising the chisel is practical and effective to harvest palms below $3 \mathrm{~m}$ height compare to the mechanised harvesting by utilising CKAT. The harvester feels more comfortable when using the chisel and have been able to work fast as compared to them using CKAT. According to that, it will be time-consuming for them to familiarise themselves with the new tools. Besides that, the motorised cutter has a drawback such as the vibration transferred to operate is not agronomic ally suggestible for a longer period of contact. The vibration transferred by CKAT will cause the side effect of health to the harvester when utilises it for a long period compare to utilization of the chisel.

\subsection{Times consumption on harvesting operation task.}

Based on the result the time consumption for manual sickle is much bigger than motorized cutter. The biggest differences in the time consumption can be seen on the pruning and harvesting task. The entire paired sample task in both practices shows that each task does not correlate with each other. Pruning the fronds is the most consuming time. For the overall harvesting operation, it required average 50 seconds for manual and 20 seconds for motorised.

The difference between both practices was influenced by field condition, palm canopy, operator skill and topography or harvesting path. For the canopy factor if the palm canopy is heavy the time consume for pruning will be bigger that casual. The harvesting path will affect the time consumption as the harvester will hard to move.

\subsection{Productivity}

Effective field capacity (EFC) brings in the factor of efficiency of the sample test. EFC is a way to determine the number of hectares actually covered or handled over a long period of time. The efficiency of both practices will be differentiated based on worker's productivity and hectare covered. By that, the EFC for manual covered 0.22 hectare per hour and for motorised cutter can cover 0.29 hectare per hour. Hence this study indicates that the worker's productivity for manual is lower that motorised cutter in term of field capacity. In addition, it can save time and workforce, a motorised cutter practice seen can increase the worker's productivity. Furthermore, both practices can be seen have different productivi- ty. The manual can get 4.21 tonnes per day compared to motorized can get until 7.4 tonnes per day.

\subsection{Coverage area}

The coverage area depends on the number of FFB from palm and canopy palm. The number of FFB per palm is different each palm to others palm. This different will affect the coverage area for harvesting operation. The higher the number of FFB per palm can minimize the coverage area and vice versa.

\subsection{Cost}

The cost for both practices are differentiated by the additional motorised to moving the motorised sickle. It's different to the manual practice just have a sickle and pole to operate. The used of this engine will give additional operating cost such as fuel and lubricant, repair and maintenance. Besides that the producer or estate will also bear to other additional fixed cost.

The engine maintenance cost is considered high because compare to the manual sickle it just required little maintenance to sharpening the sickle and adjustable pole. The regular maintenance required for the motorised cutter to ensure the cutter will perform with full ability for harvesting. The total cost which includes operating and fixed cost for motorised significantly higher than manual sickle. RM64.98 per day for motorised and RM42.69 for manual sickle. However, the most important is the cost per tonne for manual sickle is RM10.14 per tonne and RM 8.78 per day for motorised. We can conclude that the best cost for harvesting operation is motorised because its much lower than manual sickle. Although the cost for manual is much higher, the company still wants the manual labour to do the harvesting operation in some area. In addition the company is still implement the manual sickle because of other restraints such as topography, harvester skill and other factors that the company still can't manage properly.

\section{Conclusion}

Due to the serious labour shortage in plantation, a producer should seek an opportunity by taking advantage and fully utilising the available harvesting technology in order to improve the efficiency of harvesting application in the field. It can be improved by using the available technology which can enable the producer to get maximum benefits out of this important operation need to be secure its interval. The producers aimed to achieve the highest worker productivity at the lowest cost.

\section{Recommendation}

The recommendation, this study needs to expand to all variable and to get an exact result do the comparative study in the same plot or block, same variety and same plant ages. In addition the industries need to do innovation or research and development to improve the motorized cutter. This is because the motorised is still need much manpower to handle or bring the motorised. The industries must develop a new smart cut for harvesting, which not needs a man powers because of the labour shortage in the future.

As a recommendation, the additional studies should be on the comparing manual harvesting technique and mechanised harvesting technique in various areas, the age of the palms and height of palms in order to determine which one of harvesting technique more efficient and give better returns. In addition, the industries need to do innovation or research and development to improve the mechanised harvesting tools. The industries must develop a technology of harvesting tools that is comfortable for all people and can increase fresh fruit bunch productivity. 


\section{References}

[1] Kamruddin R, Rukunuddin I, Seng O. Agricultural engineering research and development in Malaysia. United Nation Asian and Pacific Centre for Agricultural engineering and Machinery (APCAEM): Beijing, China. 2007:20-3.

[2] Veloo., Hitam. Plantation labour: Need for management strategy. 2011.

[3] Jahan A, Ismail MY, Shuib S, Norfazidah D, Edwards K. An aggregation technique for optimal decision-making in materials selection. Materials \& Design. 2011;32(10):4918-24.

[4] Basiron Y. Palm oil production through sustainable plantations. European Journal of Lipid Science and Technology. 2007;109(4):289-95.

[5] Rijk AG. Agricultural mechanization strategy. Plant Production Engineering. 1999;3:536-53. 